\title{
Molecular defense response of oil palm to Ganoderma infection
}

\begin{abstract}
Basal stem rot (BSR) of oil palm roots is due to the invasion of fungal mycelia of Ganoderma species which spreads to the bole of the stem. In addition to root contact, BSR can also spread by airborne basidiospores. These fungi are able to break down cell wall components including lignin. BSR not only decreases oil yield, it also causes the stands to collapse thus causing severe economic loss to the oil palm industry. The transmission and mode of action of Ganoderma, its interactions with oil palm as a hemibiotroph, and the molecular defence responses of oil palm to the infection of Ganoderma boninense in BSR are reviewed, based on the transcript profiles of infected oil palms. The knowledge gaps that need to be filled in oil palm-Ganoderma molecular interactions i.e. the associations of hypersensitive reaction (HR)-induced cell death and reactive oxygen species (ROS) kinetics to the susceptibility of oil palm to Ganoderma spp., the interactions of phytohormones (salicylate, jasmonate and ethylene) at early and late stages of BSR, and cell wall strengthening through increased production of guaiacyl (G)-type lignin, are also discussed.
\end{abstract}

Keyword: Ganoderma; Oil palm; Elaeis guineensis Jacq.; Basal stem rot; Molecular defence; Lignin 